\title{
Thermal Studies of the Starch and Polyvinyl Alcohol based Film and its Nano Composites
}

Susmita Dey Sadhu*, Anshuman Soni and Meenakshi Garg

Department of Polymer Science, Bhaskaracharya College of Applied Sciences Sector-2, Dwarka, New Delhi, India

\begin{abstract}
Starch is a naturally occurring biopolymer with sustainable resource. This biopolymer has lower tensile strength To overcome this, it is blended with Poly-vinyl Alcohol (PVA), which is a synthetic polymer but biodegradable and biologically safe. Nanocomposite of this blend has been prepared with $1 \%, 2 \%$ and $3 \%$ nanoclay loading. The thermal properties of this polymer have been studied. In this paper, the thermal characterization using Differential Scanning Calorimetry (DSC) and Thermogravimetric Analysis (TGA) of this blend and its nanocomposites has been done.
\end{abstract}

Keywords: Polyvinyl alcohol; Starch; Thermogravimetric analysis; Differential scanning calorimetry; X-ray diffraction technique

\section{Introduction}

Starch is a naturally occurring biopolymer which is available in abundance from various sources. One of the major such source is potato, which is readily available and can also be considered as one of the sustainable source of starch. But starch itself has certain limitations e.g., low strength, low elongation, high brittleness etc. Thus to enhance its properties it is mixed with Polyvinyl alcohol (PVA), which is synthetic but non toxic, biodegradable and food safe.

Increasing use of synthetic polymers and inadequate recycling of the same has increased the environment safety concerns. Thus replacement of the synthetic polymers with biopolymers as much as possible may be considered as one step ahead towards the green method. Biopolymers having sustainable resource may solve the environment related issues to a great extent. With this idea a lot of researchers worldwide are now working on biopolymers based blends for various polymeric applications and are trying to replace synthetic polymers with biopolymers as much as possible. In our earlier communication, the mechanical properties of the starch-PVA based nanocomposites have already been discussed [1].

In recent years many scientific groups are working on various renewable natural/ biopolymer based blends and composites [2,3]. Among different types of biopolymer like starch, cellulose, chitosan, polylactic acid [4-8] etc. starch is one of the most easily available, cheap and sustainable biopolymer. Moreover starch is available from various sources like potato starch, corn starch, wheat starch etc. Literature study reveals that addition of starch to various synthetic polymers not only improves the biodegradability of the end material but also reduces cost with better acceptability interns of properties.

Starch has been added to low density polyethylene, High density polyethylene, PVA [9-12] and many more synthetic polymers.

In this paper, the focus is on the thermal studies of the cross linked starch-PVA blend and its nanocomposites with different loadings. The starch and PVA have been mixed at equal ratios. Further the addition of nano clay, Cloisite 30B has modified the proper- ties of the blend. In this study of thermal properties, X-Ray diffraction results are also provided to support the data.

\section{Experimental}

\section{Materials used}

Starch: Soluble starch of Analytical Grade is used for the work.
Starch comes in the form of white or almost white powder. The supplier of the starch is $\mathrm{CDH}^{(\mathrm{R})}$.

Polyvinyl alcohol: Poly vinyl alcohol is purchased from Loba Chemie Pvt. Ltd., Mumbai, with a degree of polymerisation 1700-1800.

Citric acid: Citric acid is purchased from local Market.

Nanoclay: Cloisite 30B is generously supplied by Souther Clay Products, USA.

\section{Instruments used}

X-Ray diffraction: Polymer Film samples have been scanned through a speed of $2^{\circ} \mathrm{C} / \mathrm{min}$ at ambient temperature using $\mathrm{X}$-ray diffract meter. The data are collected from $2 \theta^{\circ}=0^{\circ}$ to $2 \theta^{\circ}=40^{\circ}$ interval using Rigaku Ultima X-Ray Diffraction Machine.

Differential Scanning Calorimetry (DSC): Differential Scanning Calorimetry has been done using Universal V4.5A TA Instruments, DSC Q200 V24.4 Build 116 in the tempera- ture range $-50^{\circ}$ to $150^{\circ} \mathrm{C}$. The heating rate used is $10^{\circ} \mathrm{s}$ per minute in air.

Thermogravimetric Analysis (TGA): Thermogravimetric Analysis has been done using a Universal V4.5A TA Instruments, TGA Q500 V20.10 Build 36 instrument. The Experiments have been carried out from room temperature to $800^{\circ} \mathrm{C}$ at heating rate $10^{\circ} \mathrm{s}$ per minute in air.

Preparation of Starch-Polyvinyl Alcohol Film (Starch-PVA): Starch-PVA was taken in water in different composition, Like 30:70, 50:50, 70:30. The reaction mixture was heated at $70^{\circ} \mathrm{C}$ until uniformity appears, after cooling solution at $35^{\circ} \mathrm{C}$, the solution is poured onto casting mold and dried under oven at $60^{\circ} \mathrm{C}$ to remove water contents. After complete drying, the films are stored in moisture free environment.

*Corresponding author: Susmita Dey Sadhu, Department of Polymer Science, Bhaskaracharya College of Applied Sciences Sector-2, Dwarka, New Delhi 110075, India, Tel: +91-9910028035; E-mail: susmitasadhu@hotmail.com

Received November 10, 2015; Accepted November 30, 2015; Published December 10, 2015

Citation: Sadhu SD, Soni A, Garg M (2015) Thermal Studies of the Starch and Polyvinyl Alcohol based Film and its Nano Composites. J Nanomedic Nanotechnol S7:002. doi:10.4172/2157-7439.S7-002

Copyright: (c) 2015 Sadhu SD, et al. This is an open-access article distributed under the terms of the Creative Commons Attribution License, which permits unrestricted use, distribution, and reproduction in any medium, provided the original author and source are credited. 
Preparation of starch-PVA based nano composites: A specified amount of Nano Clay (1\%,2\%,3\% by wt. of starch-PVA used) was dissolved in the starch-PVA solution. The starch solution containing the clay was heated to $70^{\circ} \mathrm{C}$, held at that temperature for $20 \mathrm{~min}$, then cooled to $50^{\circ} \mathrm{C}$ and poured onto petridish and kept in an oven at $60^{\circ} \mathrm{C}$ for drying and peeled off.

\section{Discussion}

\section{X-Ray Diffraction Studies (XRD)}

The X-ray Diffraction studies have been conducted on the starchPVA blend based nano composite samples where the Cloisite $30 \mathrm{~B}$ clay loading has been varied. The XRD spectra of the starch-PVA blend with $1 \%, 2 \%$ and $3 \%$ nanoclay loading have been shown in the Figures 1-3 respectively. The comparison of these XRD results shows that there are no peaks at the lower angle from 0 to $10^{\circ} \mathrm{s}$. XRD peaks in this range are generally known to be indicative of the presence nano clay layered structure. At around $29^{\circ} \mathrm{s}$ there is a sharp peak in all the three clay filled nano composite XRD figures which appears because of the polymer crystallinity. There is a small hump around $15^{\circ}$ in $1 \%, 2 \%$ and $3 \%$ clay loaded samples. The peaks around $20^{\circ}$ s and $29^{\circ}$ s are present in all the three compositions. Literature search results have shown a peak at around $20^{\circ}$ s for Polyvinyl Alcohol [2] and at around $15^{\circ}$ and $28^{\circ}$ for the starch [3]. Pure Cloisite $30 \mathrm{~B}$ shows a peak at $5^{\circ}$ [4]. Hence, the absence of any peak between $0^{\circ}$ to $10^{\circ}$ confirms the exfoliation of the nano clays in all the compositions. The appearance of the other three peaks at $15^{\circ} \mathrm{s} ; 20^{\circ}$ and $29^{\circ} \mathrm{s}$ contribute to the presence of PVA and starch. The positions of all the three peaks remains unchanged in all the three clay loaded compositions, which indicates that there is no change in the crystalline structure or pattern of the component materials. However the intensities of the peaks have varied in all the three cases. The variations of intensities of the above mentioned three peaks in the three compositions refer to the interference of nano clay at $1 \%$ and $2 \%$ loading with the crystalline phases of both PVA and starch. That is why the peak at $15^{\circ}$ and at $20^{\circ}$ (due to starch) is not so prominent. At $3 \%$ clay loading, probably the nanoclay starts to form agglomerates and hence does not interfere with the crystalline structure of the constituent polymers leading to sharper peaks. The variations in the XRD peak intensities are observed mainly with the peak at $29^{\circ}$ which appears due to PVA. This also indicates towards the interaction of the nano fillers (Figure 1) with the PVA phase in preference to the starch phase. Whenever the nano clay interacts with the PVA phase, the corresponding peak intensities are affected. That is why; the peaks in Figure 3 are much more sharp and distinct. This explanation of the variation of peak intensities may further be confirmed by DSC results (Figures 2 and 3 ).

\section{Thermogravimetric Analysis (TGA)}

TGA has been done for all the samples with and without nanoclay to understand the thermal stability and its behavior at high temperature. The TGA data of the PVA without any starch has also been done for reference. The PVA and all the PVA starch blends and their nano composites undergo three step degradation and the results are tabulated in the Table 1 . The thermogravimetric analysis of PVA and it is blend and composites are given below (Figures $4 \mathrm{a}$ and $4 \mathrm{~b}$ ) in $100^{\circ} \mathrm{C}$ but the $1^{\text {st }}$ peak maxima appears around $1500 \mathrm{C}$. The $2^{\text {nd }}$ and $3^{\text {rd }}$ peak maxima of the PVA appear at $350^{\circ} \mathrm{C}$ and $435^{\circ} \mathrm{C}$. Maximum amount of weight loss has occurred in the $2^{\text {nd }}$ step of degradation (Table 1 ).

When starch is added to the PVA at 50:50 ratios, the stability of the blend lowered down compared to pure PVA. The $1^{\text {st }}$ and the $2^{\text {nd }}$

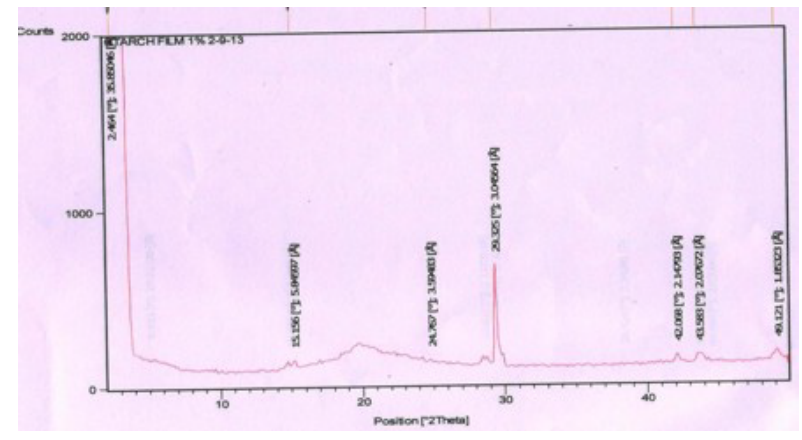

Figure 1: XRD spectra of strach-PVA blend with $1 \%$ clay loading.

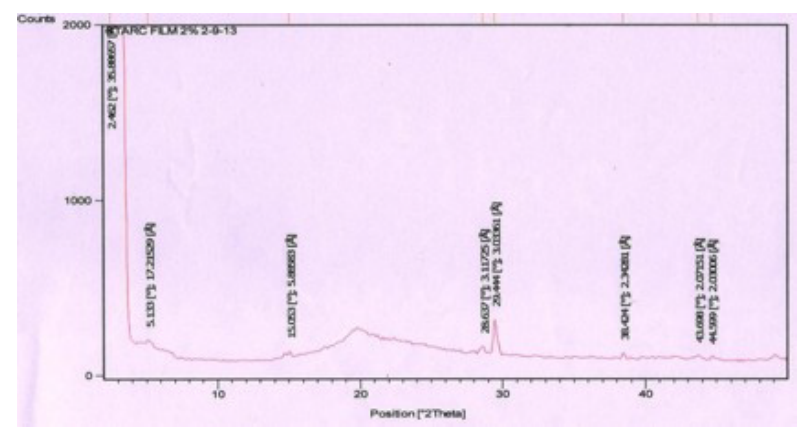

Figure 2: XRD spectra of starch-PVA blend with $2 \%$ clay loading

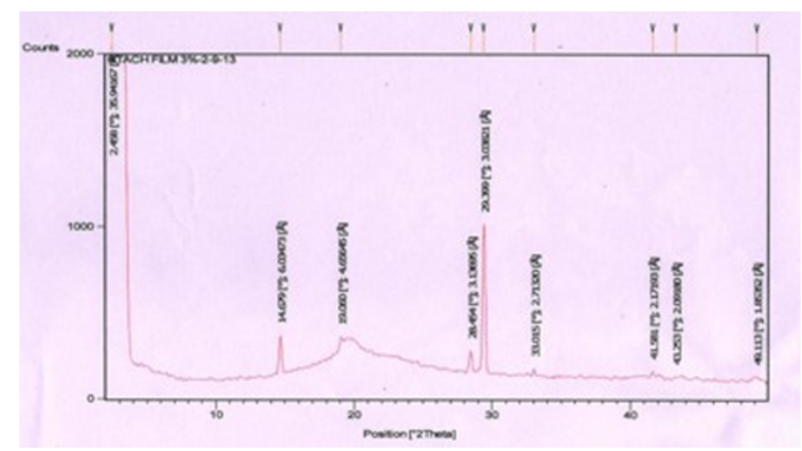

Figure 3: XRD spectra of starch-PVA blend with 3\% clay loading

\begin{tabular}{|l|c|c|c|c|}
\hline Sample & $\mathbf{1}^{\text {st }}$ peak & $\mathbf{2}^{\text {nd }}$ peak & $\mathbf{3}^{\text {rd }}$ peak & Residue Left (\%) \\
\hline PVA & 150 & 350 & 435 & \\
\hline PVA-starch blend & 70.66 & 303.58 & 437.43 & 14.92 \\
\hline PVA-starch 1\% nano & 94.86 & 284.67 & 441.97 & 23.34 \\
\hline PVA-starch 2\% nano & 109.23 & 277.87 & 443.48 & 22.06 \\
\hline PVA-starch 3\% nano & 100.91 & 278.62 & 439.7 & 23.57 \\
\hline
\end{tabular}

Table 1: TGA results of starch-PVA based samples.

degradation peak appeared at $70.66^{\circ} \mathrm{C}$ and $303.58^{\circ} \mathrm{C}$ respectively for starch-PVA $50 / 50$ blend. The $3^{\text {rd }}$ degradation peak also remained almost unchanged when compared to pure PVA. As nano clay is added to the blend at $1 \%$ and $2 \%$ loadings, the 1 st degradation peak shifted towards higher temperature from $70.66^{\circ} \mathrm{C}$ in pure starch-PVA blend to $94.86^{\circ} \mathrm{C}$ in $1 \%$ clay loaded sample to $109.23^{\circ} \mathrm{C}$ in $2 \%$ clay loaded sample. In $3 \%$ clay loaded sample the 1 st degradation peak moved slightly towards lower temperature i.e., $100.91^{\circ} \mathrm{C}$. The $2^{\text {nd }}$ degradation peak 
Citation: Sadhu SD, Soni A, Garg M (2015) Thermal Studies of the Starch and Polyvinyl Alcohol based Film and its Nano Composites. J Nanomedic Nanotechnol S7:002. doi:10.4172/2157-7439.S7-002

Page 3 of 5

continuously moves towards lower temperature as the clay loading is increased from $0 \%$ to $1 \%, 2 \%$ and $3 \%$ loading. The $3^{\text {rd }}$ degradation peak does not shift drastically. Rather it shows very slow and steady increase in the degradation peak temperature from $437.43^{\circ} \mathrm{C}$ at $0 \%$ clay loading to $441.97^{\circ} \mathrm{C}$ in $1 \%$ clay loading to $443.48^{\circ} \mathrm{C}$ in $2 \%$ clay loading to finally $439.70^{\circ} \mathrm{C}$ at $3 \%$ clay loading. The TGA curves of the PVA, starch- PVA blend at 50:50 ratio and the nano clay filled starch-PVA composites are given in Figure 4.

The results may be explained with the help of the XRD results where $1 \%$ and $2 \%$ clay loadings show good dispersion of the clay particles whereas the $3 \%$ loading shows some agglomeration. As the dispersion improves the nano clay enhances the thermal stabilities of the blends. At 3\% loading due to improper dispersion and mixing in the starch-PVA matrix, the stabilizing effect of the clays are somewhat less effective.

With loading of clay the residue increases from $14.92 \%$ in case of unfilled starch-PVA blend to $23.57 \%$ in case of $3 \%$ clay loaded starchPVA blend. The residue left in all the three clay filled samples is almost same (Figures $4 \mathrm{c}-4 \mathrm{e}$ ).

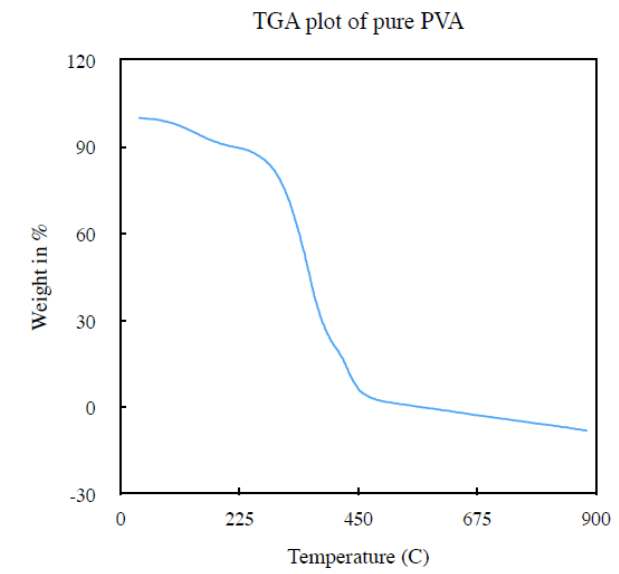

Figure 4a: TGA curves of various blends and nanocomposites. a: TGA plot of pure PVA.

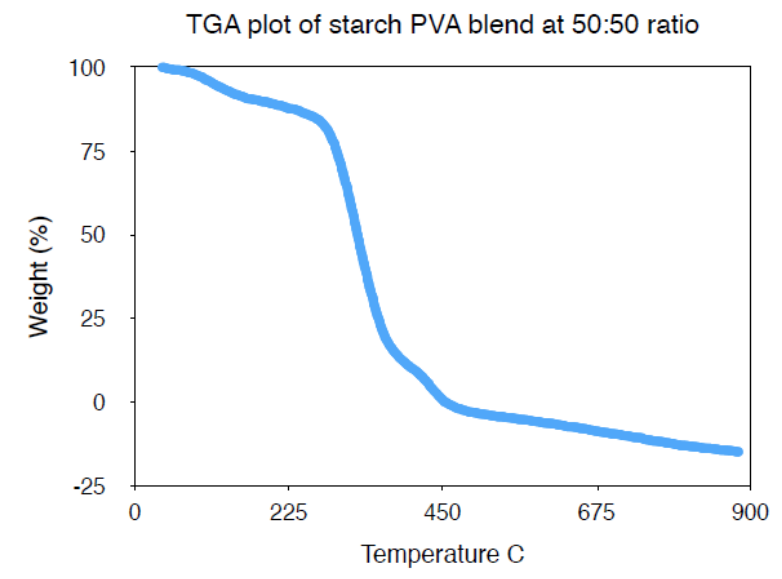

Figure 4b: TGA plot of PVA:Starch blend at 50:50 ratio.

\section{Differential Scanning Calorimeter (DSC)}

DSC has been done for two representative samples: a) starch-PVA

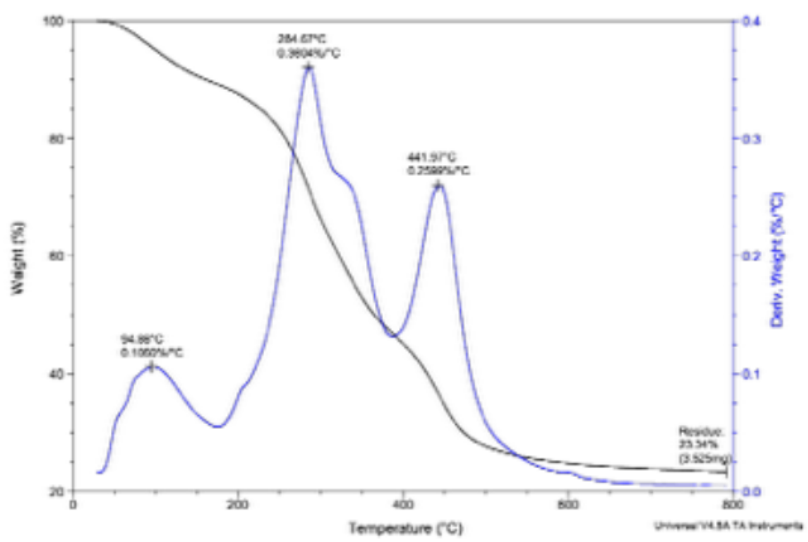

Figure 4c: TGA and DTG curve of 1\% nano clay filled starch-PVA 50:50 blend.

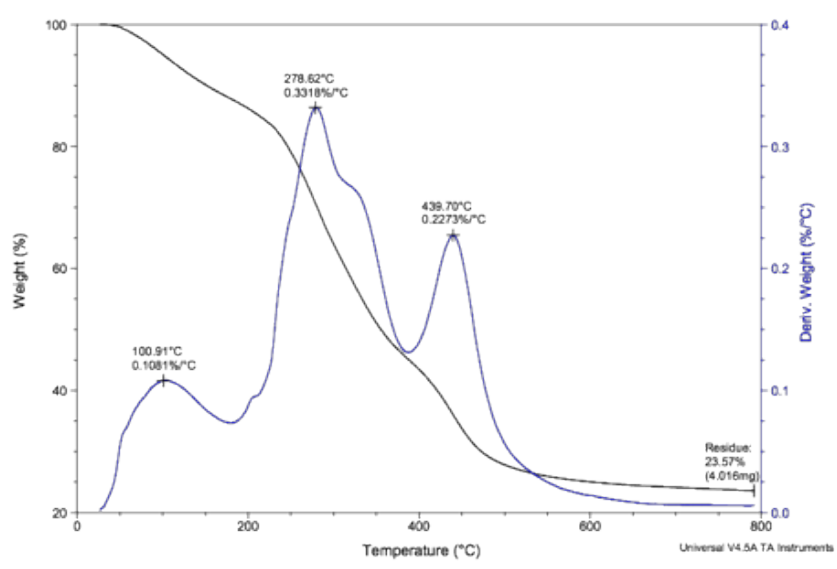

Figure 4d: TGA and DTG curve of $2 \%$ nano clay filled starch-PVA50:50 blend

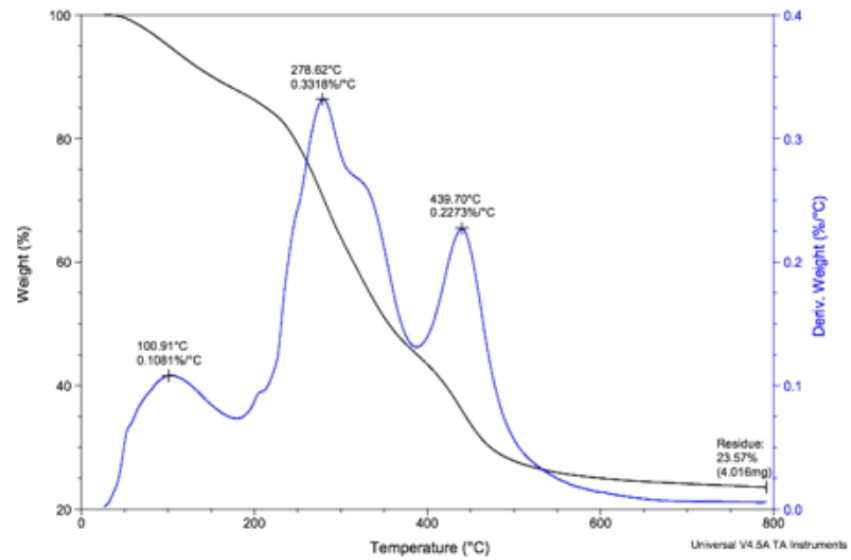

Figure 4e: TGA and DTG curve of 3\% nano clay filled starch-PVA 50:50 blend. 
Citation: Sadhu SD, Soni A, Garg M (2015) Thermal Studies of the Starch and Polyvinyl Alcohol based Film and its Nano Composites. J Nanomedic Nanotechnol S7:002. doi:10.4172/2157-7439.S7-002

Page 4 of 5

blend b) $2 \%$ nano clay filled starch-PVA blend for understanding their thermal behaviour. The DSC studies have been carried out from $-50^{\circ} \mathrm{C}$ to $150^{\circ} \mathrm{C}$. The results show that the pure starch-PVA 50:50 blend gives one exothermic peak starting at $50.39^{\circ} \mathrm{C}$ and the peak temperature at $81.82^{\circ} \mathrm{C}$ (Figure $5 \mathrm{a}$ ). Addition of $2 \%$ nano clay shifts the onset temperature by $6^{\circ} \mathrm{C}$ and peak temperature by $2^{\circ} \mathrm{C}$ towards higher temperature. A major change in the energy involved is also observed. The energy liberated in the pure blend without nano clay is $165.9 \mathrm{~J} / \mathrm{g}$ while that of starch-PVA blend with $2 \%$ nano clay is $222.4 \mathrm{~J} / \mathrm{g}$ (Figure $5 \mathrm{~b}$ ).

The XRD data of $2 \%$ nano clay filled starch-PVA blend shows better dispersion among all the clay filled samples in the polymeric matrix. With better dispersion the surface activity of the nano clay also improves. This leads to better adhesion of the clay with the polymer chains, leading to improved thermal stability of the blend. Thus the energy involvement for any type of phase change increases with better dispersed clay filled samples. This is the reason that $2 \%$ clay filled starch-PVA blend shows increase in onset temperature and the energy involvement compared to unfilled starch-PVA blend. The DSC results of the starch-PVA based samples are tabulated in Table 2 and Figures $5 a$ and $5 b)$.

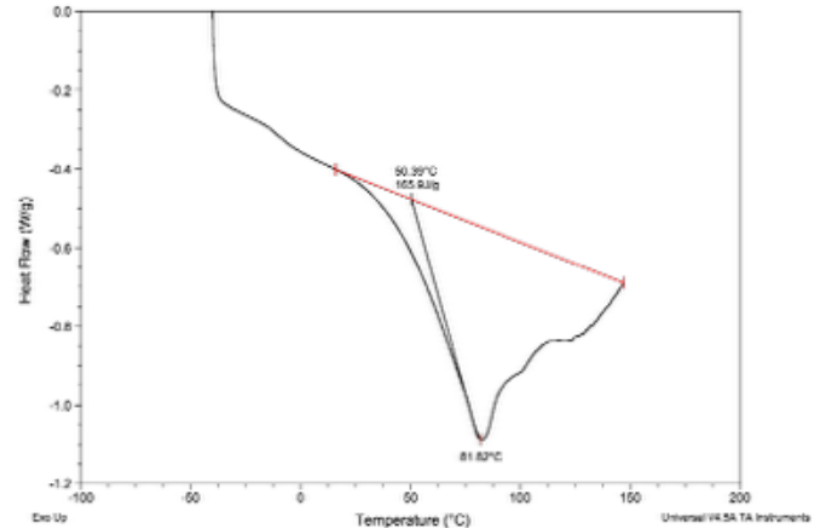

Figure 5a: DSC curve of starch-PVA based samples. a: DSC curve of starch -PVA blend at 50:50 ratio.

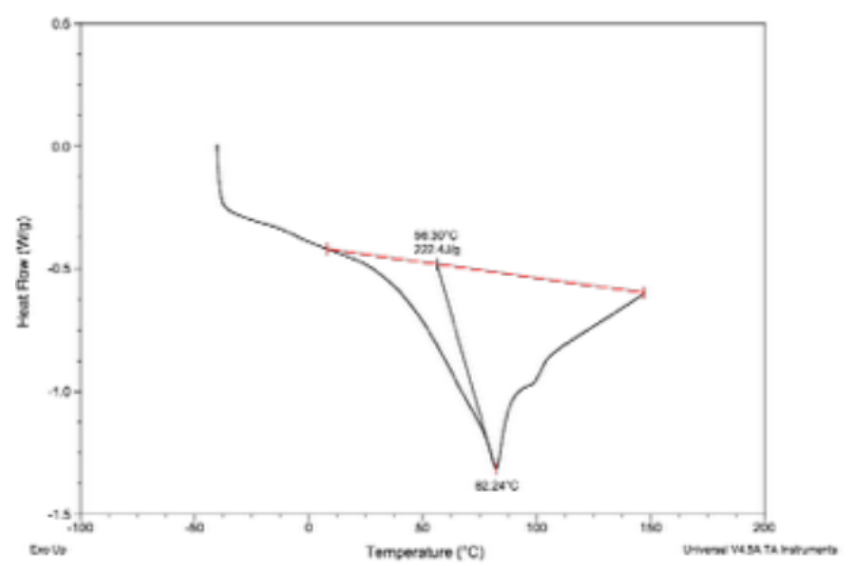

Figure 5b: DSC curve of starch-PVA blend (50:50 ratio) with $2 \%$ nano clay.

\begin{tabular}{|l|c|c|c|}
\hline Sample & $\begin{array}{c}\text { Onset } \\
\text { Temperature }\left({ }^{\circ} \mathbf{C}\right)\end{array}$ & $\begin{array}{c}\text { Peak } \\
\text { Temperature }\left({ }^{\circ} \mathbf{C}\right)\end{array}$ & $\begin{array}{c}\text { Energy Involved } \\
(\mathbf{J} / \mathbf{g})\end{array}$ \\
\hline PVA-starch blend & 50.39 & 81.82 & 165.9 \\
\hline PVA-starch + 2\% nano & 56.3 & 82.24 & 222.4 \\
\hline
\end{tabular}

Table 2: DSC results of starch-PVA samples.

\section{Conclusions}

Starch PVA blend is a biodegradable blend made from sustainable resources. This blend may be used for various applications which include food packaging, biodegradable packaging etc. as a single material or in combination with other materials. For these above mentioned applications, the studies of mechanical and thermal properties are important. Nanofillers are well known material to enhance both mechanical and thermal studies. Hence the study of thermal stability of starch-PVA nano composites is important.

The present study reveals in the XRD data that the nano fillers are well dispersed in the polymer matrix and exfoliated as there is no peak of nano clay layers till $10^{\circ}$ angle in $1 \%, 2 \%$ and $3 \%$ loading. The dispersion of the nano clay is best in case of $2 \%$ loading. The crystallinity peak of the base material that is the starch-PVA blend is also low in case of $1 \%$ and $2 \%$ loading of nano clay. In case of $3 \%$ loading of nano clay, the polymer crystalline peak intensity increases significantly indicating poor dispersion of the nano clay in the blend matrix.

The TGA studies of the unfilled and filled starch-PVA blend and pure PVA shows that addition of starch to PVA matrix has reduced the thermal stability of PVA. But addition of nano clay at $1 \%, 2 \%$ and $3 \%$ loading has increased the stability. The best stability among all the clay filled samples is shown by $2 \%$ clay loaded starch-PVA sample again confirming the optimum dispersion of the nano clay in the blend matrix.

DSC has been done for two representative samples the unfilled starch-PVA blend and $2 \%$ nano clay filled starch-PVA blend. The DSC results are in accordance with the XRD and TGA data. The 2\% clay filled blend shows higher energy involvement during the phase change confirming good interaction between the nano clay particles and polymer blend matrix.

\section{References}

1. Sadhu DS, Soni A, Varmani SG, Garg M (2014) International Journal of Pharmaceutical Science Invention 3: 33-37.

2. Yua L, Deana K, Lib L (2006) Polymer blends and composites from renewable resources. Prog Polym Sci 31: 576-602.

3. Foust CJ, Mills RR, Haas T, Castevens C, Ottenbrite RM (1997) Biodegradation of Idpe/cellulose blends by common fungi. Macromolecular Symposia 123: 1-8.

4. Sailaja RRN, Seetharamu S (2009) Mechanical and thermal properties of LDPE-cellulose acetate phthalate blends - Effect of maleic anhydride - grafted LDPE compatibilizer. Journal of Applied Polymer Science 112: 649-659.

5. Martínez-Camacho AP, Cortez-Rocha MO, Graciano-Verdugo AZ, RodríguezFélix F, Castillo-Ortega MM, et al. (2013) Extruded films of blended chitosan, low density polyethylene and ethylene acrylic acid. Carbohydr Polym 91: 666674

6. Sunilkumara M, Francisb T, Thachilc ET, Sujith A (2012) Chemical Engineering Journal 204, 206: 114-124.

7. Suyatma NE, Copinet A, Tighzert L, Coma V (2004) Mechanical and Barrier Properties of Biodegradable Films Made from Chitosan and Poly (Lactic Acid) Blends. Journal of Polymers and the Environment 12: 1-6.

8. Vert M, Mauduit J, Li S (1994) Biodegradation of PLA/GA polymers: increasing complexity. PubMed Commons below Biomaterials 15: 1209-1213.

9. Jayasekara R, Harding I, Bowater I, Christie GBY, Lonergan GT (2004) 
Citation: Sadhu SD, Soni A, Garg M (2015) Thermal Studies of the Starch and Polyvinyl Alcohol based Film and its Nano Composites. J Nanomedic Nanotechnol S7:002. doi:10.4172/2157-7439.S7-002

Page 5 of 5

Preparation, surface modification and characterisation of solution cast starch PVA blended films. Polymer Testing 23: 17-27.

10. Yoon SD, Chough SH, Park HR (2006) Effects of additives with different functional groups on the physical properties of starch/PVA blend film. Journal of Applied Polymer Science 100: 3733-3740.
11. Park HR, Chough SH, Yun YH, Yoon SD (2005) Properties of Starch/PVA Blend Films Containing Citric Acid as Additive. Journal of Polymers and the Environment 13: 375-382.

12. Jang BC, Huh SY, Jang JG, Bae YC (2001) Mechanical properties and morphology of the modified HDPE/starch reactive blend. Journal of Applied Polymer Science 82: 3313-3320. 